\title{
The Underpinning of Technical Training in Soccer Players 10-12 Years Old
}

\author{
HosseiniKhezri $\mathrm{SA}^{1 *}$ and Zaxarova $\mathrm{AV}^{2}$ \\ ${ }^{1}$ PhD of Physical Education and Sport Training, Institute of Physical Education, Sport and Youth Policy, Ural Federal University, Russia \\ ${ }^{2}$ Professor of Physical Education and Sport Training, Institute of Physical Education, Sport and Youth Policy, Ural Federal University, Russia
}

Submission: September 07, 2018; Published: September 19, 2018

*Corresponding author: HosseiniKhezri SA, PhD of Physical education and sports training. Institute of physical education and sports training. Ural Federal University, Ekaterinburg, Russia, Tel: +79634474600; Email: alihosseinikhezri@gmail.com

Abstract

The aim of this was to underpin technical training in soccer players 10-13 years old. For improving technical skills in soccer players, forty nine Russian soccer players 10-13 years old have participated in this quasi-experimental study. After modifying the complex of technical tests by our research group, the technical training was underpinned due to their mistakes in technical skills. The quality and quantity of techniques were improved after designed technical training in this age.

Keywords: Technical Training; Soccer Skills; Soccer Players; Children

\section{Introduction}

The basis of sports skills of players is the technical preparedness, the level of which largely determines the effectiveness and entertainment of the match [1-3]. However, Technical training needs do vary with age and between the sexes. Programs must be tailored to their requirements and capabilities. These considerations change according to the player's stage of development, fitness level and readiness to progress to the next training step [3-5].

Soccer training is understood as a process of systematic development of each component in dependence on the duration of preparation which leads to achieving maximum efficiency in children within the selected sports discipline [6]. Fundamental problem is the lack of a proper test to measure the technical skills in soccer players 10-12 years old, as well as the low level of technical training at this ages. In recent years, the theoretical and methodological foundations of the reserve preparation system for professional soccer were developed [7-9]. Although researchers who have documented the practice profiles of soccer performers have contributed to our awareness of the significant investment of time and effort required to reach elite levels of performance (i.e. the macrostructure of practice), there remains a lack of knowledge about the specific practice activities that players undertake on the road to excellence $[10,11]$. In particular, research is required to determine the "what" and "how" of practice [12] and which practice can be more efficiency in soccer players 10-14 years old.

\section{Material \& Methods}

Two soccer team from Russia as an Experimental group $(\mathrm{N}=22$. height $159.6 \pm 7.25 \mathrm{~cm}$; weight $46,62 \pm 6,41 \mathrm{~kg})$ and control group $(\mathrm{N}=27$. Height $160.3 \pm 5.25 \mathrm{~cm}$; weight $47,71 \pm 7$, $31 \mathrm{~kg}$ ) have participated as subject in this quasi_experimental study. They attended to Ural Federal University Stadium for technical skills assessments. It was prerequisite that the player free of injury at the time of commencement of project. Data collection according to our designed technical tests (7 technical tests). All of technical training were performed in mesocycles (12 weeks) of training which was provided by ours after testing at October 2017. Technical exercises were designed and implemented according to the level of skills from easiest to difficult. Soccer players had warmed their bodies up before exercising. In training stage of study, Different aspect of technical and physical training (related by soccer techniques) are provided by our research group and coach to improve all of technical skills in soccer players 10-12 years old.

\section{Training protocol}

The set of exercises was provided for soccer players at this age after testing (September 2017). This exercise begins from easiest to difficult for performing and learning skills more efficiently. Physical training were performed every week to improve the implementation conditions associated with controlling body and head. Eye-hand coordination exercise should be performed 
with close eyes and then throw the ball to air. After throwing open the eyes and control ball by hand with open eyes. Throwing the ball after closing eyes can improve mistakes which are related by failure of prediction of ball. Rolling a ball is good for coordination and one kind of eye foot coordination. Practice throwing and rolling objects (balls) at a target. For improving coordination, we can make change in distance of zone or target. Catching a ball with your hands, a glove or lacrosse stick is a good exercise for improving their coordination. They could also catch other things like a Frisbee. Balance + fast footwork is the sequence of high-speed jumps landing on the right and left foot in circles placed on the ground, receiving the ball and doing a slalom around poles and making a long aerial pass. In controlling body exercise, 12 players should be in a $15 \times 25 \mathrm{~m}$ square and try to throw ball to each other and then control ball with body. In the other type of controlling ball consecutive in space, every player should have a ball. They must kick to ball sequentially. They should begin first from: right leg, right hip, right shoulder, left shoulder, left hip, left leg. Controlling ball with chest and body was provided to improve controlling body and record the best scores in this technique. Controlling head exercise was provided for specially controlling by head. Physical and technical aspect of training could get better in this technique. In this exercise, two players should be in front of each other. One player should throw the ball with hand and opposite players must control ball with Head. Distance between players which are in front of each other should be $5 \mathrm{~m}$. After 10 attempt players position should be change. Controlling ball with long passing and Juggling with controlling are two mixed exercises for the end of training.

In the juggling with pass, players juggle inside playing area (every other touch must be with weaker foot). On coach's command players settle the ball with their weak foot and dribble until coach says "Juggle!" again. Player whose ball goes out of bounce does 10 squat jumps. Receiving ball while dribbling and change speed and direct according by situation are important aspect of dribbling. Soccer players at this age should perform different type of dribbling by different size of ball. Zigzag running is the first exercise which should be provide at the first stage of training. Coaches was Set up cones in a zig-zag formation. Players should perform one by one. Running with changing speed and direction is the main aspect of dribbling skills in soccer players 10-12 years old. Most of players at this age have limitation to perform dribbling because of it. Set up cones as a square and player have to running without ball around the square. Running with ball by inside and outside of foot was performed after 6 weeks of training program. This training is similar to dribbling in real match situation. Each player running as quick as possible with inside and outside of foot around the cones with ball (slalom part). Kicking with different type of passing by making different zone and distance (short pass $5 \mathrm{~m}$ ), (middle pass, 15m), (long pass or high distance pass, $35 \mathrm{~m}$ ), pay attention on targeting, Using different level of passing practice such mixed passing and shooting, Short passing with inside of foot, Passing with wall every day one by one or by group and Imagery practice are the most important approach to improve their ability in passing.

Shooting and passing are in the same basically of skills. Group exercises and personal exercises can implement in every section of training program. Shooting exercises must be under consideration real condition of match. This can make players more success in the competition. Physical training can also be one of the exercises in shooting. Targeting by hand exercise (Throwing the ball to zone like basket to increase targeting skills) was designed at the first part of exercises period. The main aspect of shooting is targeting on zone. For improving this, we would design training which are easy to do. Kicking ball to one zone can perform after targeting by hand. Try to kick the ball in static position to goal is the aim of this exercises. The place of kicking should not be mentioned at first time. After some training section they should change the distance of zone.

\section{Measurement}

Two times of testing were performed in pre and post technical exercises program (pretest=May 2017, Post Test=May 2018). The set of technical tests performed in pre exercises to measure technical level and replicated after exercises period. The tests were administered outdoors on a playing field. The players warmed-up in the usual manner before a practice session (stretching and jogging), and also as short time rested between tests. One professional soccer coach has supported and followed all test. The following tests were modified by ours and performed in this study.

Statistical analysis, all the results are reported as means standard deviation (SD). To establish the levels of technical preparedness, level indicators for each indicator using the value of the normal of the deviation equal to $\bar{X} \pm 2 / 3 \sigma$ [13-17]. Paired $\mathrm{T}$ test was calculated difference between two times of technical skills (pre and post exercises). Results were accepted as significant at ( $\mathrm{P}_{-}$0.05). Group size and statistical power were estimated using SPSS 21.

\section{Results}

Descriptive results for the seven variables studied after exercises period are presented in Table 1. The results from the $t$ tests showed how the exercises (12-week periods) were statistically significant in any of the models obtained (all $\mathrm{p}>0.05)$. The other fixed factors revealed significant differences of controlling body $(.000 ; \mathrm{p}<0.05)$, controlling head $(.000$; $\mathrm{p}<0.05)$, running without ball $(.018 ; \mathrm{p}<0.05)$ and running with ball $(.000 ; \mathrm{p}<0.01)$; passing $(.000 ; \mathrm{p}<0.05)$, shooting accuracy $(.028 ; \mathrm{p}<0.05)$, and shooting $(.917 ; \mathrm{p}<0.05)$. Table 1 shows the descriptive and $\mathrm{T}$ tests results in soccer players.

The result of above table shows that, there is no significance differences between shooting before and after exercises (sig $=.917, \mathrm{p}<0.05$ ). The descriptive analyze of this variable also was not increase by training. Pre exercises $(11.8 \pm 4.4)$ and 
post exercises (11.8 \pm 4.7$)$. However, shooting accuracy (coach selected) was improved after technical exercises. Pre exercise was $2.15 \pm 1.5$. After exercises was $3.14 \pm 1.23$. There was

significance differences between two stages of technical training $(\operatorname{sig}=.000)$

Table 1: The paired T test and description result of technical skills in soccer players 10-13 years old (EG).

\begin{tabular}{|c|c|c|}
\hline \multicolumn{1}{|c|}{ Technical Tests } & Pre Exercises & Post Exercises \\
\hline $\begin{array}{c}\text { Control of the ball by any parts of the body, except hands (juggling), number of } \\
\text { times }\end{array}$ & $70,5 \pm 48,32(11-204)$ & $117,4 \pm 76,5^{* *}(7-266)$ \\
\hline Control of the ball head, number of times & $10,3 \pm 5,65(2-21)$ & $12,2 \pm 7,34^{* *}(3-34)$ \\
\hline Running with the ball (dribbling), sec & $12,22 \pm 0,97(10.69-15,25)$ & $10,6 \pm 0,99^{*}(9.25-13.5)$ \\
\hline Running without a ball, sec (dribbling), sec & $8,34 \pm .058(7,28-9,31)$ & $7,9 \pm 0,47^{* *}(7.08-9.19)$ \\
\hline Ball transfer for accuracy, points & $1,63 \pm 0,73(0-3)$ & $3,38 \pm 1,11^{* *}(1-5)$ \\
\hline Kicking on accuracy on goal, points & $11,8 \pm 4,4(1-19)$ & $11,8 \pm 4,7^{* *}(2-20)$ \\
\hline Kicking on the accuracy of the gate zones, scores & $2,15 \pm 1,5(0-5)$ & $3,14 \pm 1,23^{* *}(1-5)$ \\
\hline
\end{tabular}

Note: ${ }^{*}-p<0.05$ differences are reliable; ${ }^{* *}-p<0.01$ differences are reliable.

Table 2: Results of technical preparedness of football players $12-13$ years before and after the experiment $(M \pm S D(\min -\max )$ ).

\begin{tabular}{|c|c|c|c|c|}
\hline \multirow{2}{*}{ Technical aspects } & \multicolumn{2}{|c|}{ Experimental Group } & \multicolumn{2}{|c|}{ Control Group } \\
\cline { 2 - 5 } & Before EXP & After EXP & Before EXP & After EXP \\
\hline $\begin{array}{c}\text { Control of the ball by any parts of } \\
\text { the body, except hands (juggling), } \\
\text { number of times }\end{array}$ & $70,5 \pm 48,32(11-204)$ & $117,4 \pm 76,5^{* *}(17-266)$ & $122,8 \pm 119,2(13-550)$ & $142,5 \pm 123,09(11-500)$ \\
\hline $\begin{array}{c}\text { Control of the ball head, number } \\
\text { of times }\end{array}$ & $10,3 \pm 5,65(2-21)$ & $12,2 \pm 7,34^{* *}(3-34)$ & $11,1 \pm 6,47(3-25)$ & $10,2 \pm 6,6(3-26)$ \\
\hline $\begin{array}{c}\text { Running with the ball (dribbling), } \\
\text { sec }\end{array}$ & $12,22 \pm 0,97(10.69-15,25)$ & $10,6 \pm 0,99^{*}(9,25-13,5)$ & $9,81 \pm 0,9(8,18-11,38)$ & $10,06 \pm 1,7(8,12-12,92)$ \\
\hline $\begin{array}{c}\text { Running without a ball, sec } \\
\text { (dribbling), sec }\end{array}$ & $8,34 \pm .058(7,28-9,31)$ & $7,9 \pm 0,47^{* *}(7,8-9,19)$ & $7,26 \pm 0,5(6,54-8,25)$ & $7,34 \pm 0,37(6,56-8,25)$ \\
\hline Ball transfer for accuracy, points & $1,63 \pm 0,73(0-3)$ & $3,38 \pm 1,11 * *(1-5)$ & $2,07 \pm 0,91(1-4)$ & $2,5 \pm 1,18(0-5)$ \\
\hline $\begin{array}{c}\text { Kicking on accuracy on goal, } \\
\text { points }\end{array}$ & $11,8 \pm 4,4(1-19)$ & $11,9 \pm 4,8(2-20)$ & $11,08 \pm 3,99(4-19)$ & $13 \pm 4.5(6-23)$ \\
\hline $\begin{array}{c}\text { Kicking on the accuracy of the } \\
\text { gate zones, scores }\end{array}$ & $2,15 \pm 1,5(0-5)$ & $3,14 \pm 1,23 * *(1-5)$ & $2,05 \pm 0,94(0-4)$ & $3,25 \pm 1,16(0-5)$ \\
\hline
\end{tabular}

Note: ${ }^{*}-p<0.05$ differences are reliable; ${ }^{* *}-p<0.01$ differences are reliable.

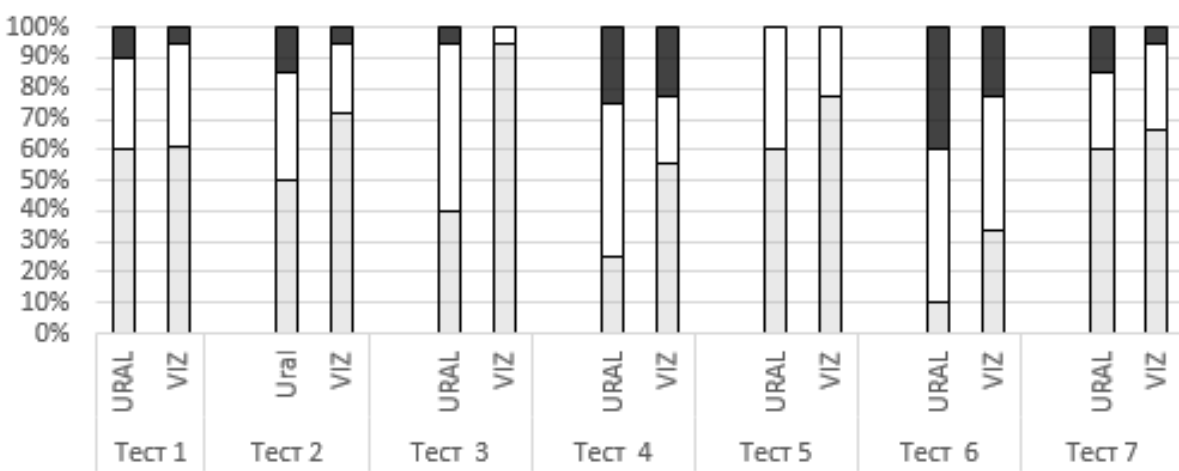

Test 1: Shooting at the accuracy of the goal

Test 2: Shooting on the accuracy of the gate zones

Test 3: Running with the ball (dribbling)

Test 4: Running without a ball

Test 5: Passing to the ball by accuracy

Test 6: Control of the ball by any part of the body, except hands (juggling)

Test 7: Control of the ball head

Figure 1: Levels of technical preparedness of football players EG and CG before experiment\%. 
Figure 1 clearly shows insufficiently developed components, which require special attention of trainers of both times. In particular, Soccer players should "pull up" the results in dribbling (without ball) $25 \%$ of them were in high level. Running with ball (Dribbling) has been improved by time but the high level of players was not improved. They recorded less than $15 \%$ in the high level of shooting accuracy (in both time). Shooting on the accuracy of the zones was in the lower than 15\% but accuracy Shooting of the goal was improved after technical exercises (more than 20\%). Most of soccer players have improved technical skills after exercises which are prerequisite for soccer players 10-12 years old (Table 2).

a) Test 1: Shooting at the accuracy of the goal

b) Test 2: Shooting on the accuracy of the gate zones

c) Test 3: Running with the ball (dribbling)

d) Test 4: Running without a ball

e) Test 5: Passing to the ball by accuracy

f) Test 6: Control of the ball by any part of the body, except hands (juggling)

\section{g) Test 7: Control of the ball head}

Analysis of the change in the distribution of participants in the EG by the levels of technical preparedness (Figure 2) as a result of the experiment indicates an increase in the technical preparedness of players: in tests 6 and 7 (ball control), the number of players who control the ball at a high level has increased, the level has been preserved; in test 5 (dribbling with movement), the proportion of players with a low running speed decreased significantly due to the transition to the middle level (60\%) and to a high level (20\%); accuracy of transfer of the ball (test 3) in the group was significantly improved due to the appearance of a high level (10\%) and a reduction in the number of players inaccurate performing passes twice; in the test (1) strikes on the accuracy of the gate zones, most of the players EG (more than 50\%) moved to the middle level. Finally, we have to consider that training should be designed in which players are provided the opportunity to practice a wide range of locomotor movements (running, skipping, hoping, galloping, leaping, etc.), no locomotor movements (Malina ding, pulling, twisting, pushing, etc.) and other movement components such as balance, change of direction, strength, and cardiovascular endurance.



Test 1: Shooting at the accuracy of the goal

Test 2: Shooting on the accuracy of the gate zones

Test 3: Running with the ball (dribbling)

Test 4: Running without a ball

Test 5: Passing to the ball by accuracy

Test 6: Control of the ball by any part of the body, except hands (juggling)

Test 7: Control of the ball head

Figure 2: Levels of technical preparedness of football players EG before and after the experiment\%.

\section{Conclusion}

Thus, the level of technical preparedness of the players of the experimental group was significantly improved after the experiment. The number of players demonstrating a high level of preparedness in carrying out the main components of technical skills has increased in controlling the ball by body and head parts, ball transfers, dribbling speeds and impacts on the gate zones. Statistically, the running speed of the dribbling track without the ball and the attacks on the least protected gates were not changed significantly. But if the improvement of running time without the ball was not included in the tasks of our research, then the work on the accuracy of the shots on the goal must be continued.

\section{References}

1. Menz HB (1998) Alternative techniques for the clinical assessment of foot pronation. Journal of the American Podiatric Medical Association 88(3): 119-129.

2. Halson SL (2013) Recovery techniques for athletes. SSE 26: 1-6.

3. Rebelo A, J Brito, J Maia, M Coelho-e-Silva, A Figueiredo, et al. (2013) Anthropometric characteristics, physical fitness and technical 
performance of under-19 soccer players by competitive level and field position. International journal of sports medicine 34(4): 312-317.

4. Franks A, A Williams, T Reilly, A Nevill (1999) Talent identification in elite youth soccer players: Physical and physiological characteristics. Journal of Sports Sciences 17(10): 812.

5. Thierry Barnerat MR (2005) Fifa Coaching. Switserland, Fifa

6. Perroni F, M Vetrano, G Camolese, L Guidetti, C Baldari (2015) Anthropometric and somatotype characteristics of young soccer players: Differences among categories, subcategories, and playing position. The Journal of Strength \& Conditioning Research 29(8): 2097-2104.

7. Shea CH, G Wulf, JH Park, B Gaunt (2001) Effects of an auditory model on the learning of relative and absolute timing. Journal of motor behavior 33(2): 127-138.

8. Myer GD, KR Ford, JL Brent, TE Hewett (2006) The effects of plyometric vs. dynamic stabilization and balance training on power, balance, and landing force in female athletes. The Journal of Strength \& Conditioning Research 20(2): 345-353.

9. Ramírez-Campillo R, CH Burgos, C Henríquez-Olguín, DC Andrade, C Martínez, et al. (2015) Effect of unilateral, bilateral, and combined plyometric training on explosive and endurance performance of young soccer players. The Journal of Strength \& Conditioning Research 29(5) 1317-1328.

10. Lidor R, G Tenenbaum, G Ziv, V Issurin (2016) Achieving Expertise in
Sport: Deliberate Practice, Adaptation, and Periodization of Training Kinesiology Review 5(2): 129-141.

11. Manolopoulos K, I Gissis, C Galazoulas, E Manolopoulos, D Patikas, et al. (2016) Effect of combined sensorimotor-resistance training on strength, balance, and jumping performance of soccer players. The Journal of Strength \& Conditioning Research 30(1): 53-59.

12. Janelle CM, CH Hillman (2003) Expert performance in sport. Expert performance in sports: Advances in research on sport expertise p. 1947.

13. Prosandeyev P (2007) Pedagogical control over technical preparedness of young football players: disk and Ped Sciences, PP Prosandeyev Surgut.

14. Semenov LA (2011) Introduction to research and development in the field of physical culture and sports.

15. Ben Ounis O, A BenAbderrahman, AA Karim Chamari, M BenBrahim A Hammouda, et al. (2013) Association of short-passing ability with athletic performances in youth soccer players. Asian journal of sports medicine 4(1): 41-48.

16. Cordun M (2009) Kinantropometrie, Cd Press.

17. Malina RM, SP Cumming, AP Kontos, JC Eisenmann, B Ribeiro, et al (2005) Maturity-associated variation in sport-specific skills of youth soccer players aged 13-15 years. Journal of sports sciences 23(5): 515522.

\section{Your next submission with Juniper Publishers} will reach you the below assets

- Quality Editorial service

- Swift Peer Review

- Reprints availability

- E-prints Service

- Manuscript Podcast for convenient understanding

- Global attainment for your research

- Manuscript accessibility in different formats

( Pdf, E-pub, Full Text, Audio)

- Unceasing customer service

Track the below URL for one-step submission https://juniperpublishers.com/online-submission.php 